\title{
CARACTERIZAÇÃO DO AMBIENTE DE INOVAÇÃO DE UMA EMPRESA DE INFORMAÇÕES PARA DECISÃO DE NEGÓCIOS
}

\section{CHARACTERIZATION OF INNOVATION ENVIRONMENT OF A INFORMATION COMPANY FOR BUSINESS DECISION}

\author{
Marcelo Macedo ${ }^{1}$; Leonardo Muller ${ }^{2}$; Márcia Adriana Tomaz Duarte ${ }^{3}$ \\ ${ }^{1}$ Instituto Superior Tupy - IST/Sociesc - Joinville - Brasil \\ marcelo.macedo@sociesc.org.br \\ ${ }^{2}$ Instituto Superior Tupy - IST/Sociesc - Joinville - Brasil \\ leomuller11@gmail.com \\ ${ }^{3}$ Instituto Superior Tupy - IST/Sociesc - Joinville - Brasil \\ marcia.duarte@sociesc.org.br
}

\begin{abstract}
Resumo
A importância do tema inovação e o desejo em contribuir para o meio acadêmico e empresarial justificam este trabalho, que teve como objetivo identificar características que potencializam ou inibem a inovação no ambiente de uma empresa de informações para decisão de negócios. As etapas da pesquisa contemplaram o referencial teórico de publicações sobre a inovação, o levantamento dos principais fatos históricos da empresa e a aplicação do questionário Minnesota Innovation Survey (MIS), que analisa 29 dimensões divididas nos fatores de influência: ideias, contexto, pessoas, transações e resultados. O presente estudo é caracterizado como descritivo $e$ quantitativo. $O$ trabalho apresentou como resultado a análise dos fatores de influência do ambiente e sua contribuição para o desenvolvimento do processo de inovação na empresa estudada, permitindo afirmar que o ambiente analisado é propício à inovação, evidenciado pelas dimensões: eficiência percebida com a inovação, incerteza sobre a inovação, liberdade para expressar dúvidas, dependência de recursos, formalização no relacionamento, influência entre grupos, estágio da inovação, problemas identificados, complementaridade, liderança do time de inovação, aprendizagem encorajada, eficiência do relacionamento, escassez de recursos, grau de novidade, conflitos, processo de resolução de conflitos, duração do relacionamento, tempo dedicado à inovação, frequência da comunicação entre grupos e consenso/conflitos. No ambiente analisado, foram identificadas apenas duas dimensões consideradas pelos participantes do estudo como inibidoras à inovação: A padronização de procedimentos e a frequência da comunicação.
\end{abstract}

Palavras-chave: Inovação; Ambiente de inovação; Organização.

\section{Introdução}

De acordo com Govindarajan e Trimble (2010) as empresas não foram concebidas para inovar, e sim para serem eficientes. São grandes as pressões diárias e existe dificuldade em ajustar a disciplina através da eficiência, com a disciplina através da inovação. Grande parte das 
organizações possuem criatividade e tecnologia, porém não possuem capacidade de gestão para transformar ideias em realidade. Tushman e Nadler (1997) argumentam que as empresas inovadoras são aquelas que desenvolvem soluções que atendam as necessidades de quem as utiliza, possuem autonomia e identificação organizacional, assumem riscos e toleram o fracasso, apresentam eficácia funcional e organizacional, demonstram altos padrões de desempenho e incentivam o desenvolvimento das pessoas.

Segundo Leite (2005), o processo de inovação sofre influência direta do ambiente organizacional. Uma invenção geralmente não é previsível, mas os gestores das empresas devem propiciar um ambiente favorável a novas ideias, padrões, mecanismos e analogias interpessoais adaptados e que beneficiem a inovação. Van de Ven, Angle e Poole (2000) ressaltam que o processo de inovação é consequência da relação entre o meio interno e os acontecimentos sucedidos no meio externo da organização. Estes fatos estimulam as transformações, fazendo com que a equipe adote novas posturas, refletindo no ambiente através de inovações.

Cabe destacar também a teoria de Nonaka e Takeuchi (1997). Para os autores, a geração de conhecimento, e por resultado a inovação, precisa de um contexto para ser criada. A origem desse ambiente acontece em um " $b a$ ”(tradução de lugar), considerado um espaço mental e social para a assimilação da informação e interação, servindo como base para criação de inovações e conhecimentos.

Nesse contexto, buscou-se neste trabalho caracterizar o ambiente de inovação de uma empresa líder de mercado na área de serviço de informações de crédito, por meio da aplicação da metodologia desenvolvida por um grupo de pesquisa da Universidade de Minnesota, denominado Minnesota Innovation Survey (MIS), que analisa diversas dimensões do ambiente organizacional, com o intuito de evidenciar características de um ambiente propício à inovação, considerando fatores internos e externos. Diante do exposto, a pergunta que norteia esta pesquisa é a seguinte: A empresa em estudo propicia um ambiente favorável à inovação?

\section{Inovação}

De acordo com Govindarajan e Trimble (2010), até pouco tempo atrás, os pesquisadores das academias não haviam ingressado a fundo na área da inovação. Na década de 1990 novos estrategistas afirmavam que seria inútil atuar defensivamente, pois poderiam ocorrer interrupções nas mudanças, causando reduções de vantagens competitivas. As organizações contrárias às mudanças, aquelas que não fossem inovadoras, fatalmente deixariam de existir. A estratégia passa a ser a inovação. Esse novo ponto de vista é acolhido de forma ampla e os estudiosos cada vez mais aprimoram suas ideias sobre a relação entre estratégia e inovação. Na opinião dos autores, ao optar por colocar uma ideia no mercado, uma organização necessita realizar longos períodos de pesquisa, 
constituição de protótipos, sessões de brainstorming, vasta pesquisa de mercado, análises estratégicas, modelagem financeira e finalmente, mas não menos importante, a execução.

A inovação fundamenta-se na compreensão do que torna possível a mudança da condição de invenção para inovação. É a oferta no mercado ou a relação no meio social das invenções, representando a articulação de duas situações diferentes, a do descobrimento, independente da lógica de mercado e a da utilização social com a possibilidade de obter resultados financeiros com a invenção (ALTER, 2001).

Para Van de Ven, Angle e Poole (2000) a inovação é, sobretudo, um método de criação e aplicação de uma novidade, compreendendo novos métodos ou o desenvolvimento de novas ideias, como uma nova técnica, artigo, processo ou arranjos. Os autores afirmam ainda que as novas ideias podem ser uma combinação de ideias antigas, desafiando a ordem atual, em resumo, uma nova percepção pelos envolvidos. De acordo com o Manual de Oslo, publicado pela OCDE (2005, p. 55): "uma inovação é a implementação de um produto (bem ou serviço) novo ou significativamente melhorado, ou um processo, ou um novo método de marketing, ou um novo método organizacional nas práticas de negócios, na organização do local de trabalho ou nas relações externas".

Para Afuah (2003), a inovação de produto é o oferecimento de um artigo com custo menor, com propriedades diferentes ou somente algo novo e que tenha relação a um conhecimento inédito e ainda represente novidade para os consumidores. O Manual de Oslo (2005) define a inovação de processo como sendo a aplicação de uma metodologia de produção ou distribuição inédita ou com melhorias importantes, compreendendo mudanças em equipamentos, softwares ou técnicas.

A inovação em marketing refere-se a implementação de alterações expressivas na criação de um produto ou da embalagem, nas táticas de promoção ou na definição de preços. Tais inovações alcançam novos mercados, ou realocam determinados produtos no mercado, aumentando o faturamento das empresas. Ainda de acordo com o manual, inovação em marketing está relacionada à implantação de novos modelos de venda de bens e serviços, implantação de sistema de informação customizado, mudanças no desenho dos produtos e inovação constante da marca. A inovação organizacional acontece quando um novo método organizacional é aplicado nas práticas de negócio da empresa, na organização do local de trabalho. Estas mudanças focam a melhoria da performance de uma organização através da redução de despesas administrativas ou despesas transacionais, ou pela redução da necessidade de suprimentos. Novos procedimentos organizacionais nas relações externas da empresa englobam novos meios para estabelecer a relação com outras empresas (MANUAL DE OSLO, 2005). 


\section{Minnesota innovation research program - MIRP}

O método denominado MIRP (Minnesota Innovation Research Program) é resultado de um estudo de dezessete anos, realizado por pesquisadores da Universidade de Minnesota, para compreender como acontece o processo de inovação, desde a criação até a implantação de uma nova ideia, apresentada por pessoas, que possuem ligações umas com as outras nas esferas da empresa. O estudo foi baseado na linha do tempo dos acontecimentos, fatores de inovação e setores da economia (Figura 1). Três elementos foram imprescindíveis para os pesquisadores do MIRP: moderação, significância e generalidade (VAN DE VEN; ANGLE; POOLE, 2000).

Ainda de acordo com os autores, os pesquisadores foram divididos em quatorze grupos, com especialistas de diversas áreas, para compreender a gestão de inovação e sua evolução através de estudos de casos analisados individualmente, coletivamente e organizacionalmente, por setores e no âmbito nacional. As pesquisas foram realizadas em empresas privadas, públicas e do terceiro setor, possibilitando identificar fatores básicos (descritos no Quadro 1) que ocorreram nos casos pesquisados.

Quadro 1 - Comparação entre literatura convencional e MIRP

\begin{tabular}{|l|l|l|}
\hline Fatores & Literatura convencional & MIRP \\
\hline Ideias & Uma invenção, operacionalizada. & $\begin{array}{l}\text { Reinvenção, proliferação, reimplementação, } \\
\text { descarte, término. }\end{array}$ \\
\hline Pessoas & $\begin{array}{l}\text { Um empresário com uma equipe fixa } \\
\text { em período integral ao longo do tempo. }\end{array}$ & $\begin{array}{l}\text { Muitos empreendedores, fluidamente engajados, e } \\
\text { desengajados ao longo do tempo em uma série de } \\
\text { regras organizacionais. }\end{array}$ \\
\hline Transações & $\begin{array}{l}\text { Grupo fixo de pessoas, e ou empresas } \\
\text { elaborando detalhes de uma ideia. }\end{array}$ & $\begin{array}{l}\text { Expansão da rede e envolvidos, que se expandem e } \\
\text { contraem no decorrer do tempo, divergentes e } \\
\text { convergentes sobre as ideias. }\end{array}$ \\
\hline Contexto & $\begin{array}{l}\text { Ambiente propicia oportunidades e } \\
\text { restrições ao processo de inovação. }\end{array}$ & $\begin{array}{l}\text { Processo de inovação restringido pelo contexto e } \\
\text { criando múltiplos ambientes ordenados. }\end{array}$ \\
\hline Resultado & $\begin{array}{l}\text { Orientação do resultado final vem a ser } \\
\text { uma nova ordem estável. }\end{array}$ & $\begin{array}{l}\text { Resultado final pode ser indeterminado; dinâmica } \\
\text { contraditória entre os gestores da inovação e os } \\
\text { controladores dos recursos; integração de novos e } \\
\text { antigos resultados. }\end{array}$ \\
\hline Processo & $\begin{array}{l}\text { Sequência simples, com estágios } \\
\text { cumulativos. }\end{array}$ & $\begin{array}{l}\text { Múltiplos caminhos, convergentes, divergentes e } \\
\text { paralelos. Alguns relacionados e cumulativos, } \\
\text { outros não. }\end{array}$ \\
\hline
\end{tabular}

Fonte: Van de Ven, Angle e Poole (2000)

\section{Procedimento metodológico}

A base do trabalho foi a metodologia do questionário Minnesota Innovation Survey (MIS), descrito por Van de Ven, Angle e Poole (2000), fruto de estudos realizados por pesquisadores do Minnesota Innovation Research Program (MIRP), buscando a compreensão a respeito do processo de gestão e desenvolvimento de inovações, através de pesquisas que envolvem inovações em produtos, processos e administrativas. Sua fundamentação possibilitou interpretar a percepção dos 
envolvidos no processo de inovação, desde a fase do surgimento da ideia até sua implantação. Levou-se em consideração 29 dimensões da pesquisa realizada por Van de Ven, Angle e Poole (2000) e já testados no Brasil por Barbieri (2004), Machado (2004), Vicenti (2006), Knop (2008), Barzotto (2008), Valadares (2008) e Matsuzawa (2008).

Devido à pretensão do estudo em identificar características de um ambiente inovador, foi escolhida de maneira intencional e não probabilística a empresa analisada, pelo fato de ter destacada em sua visão à busca pela inovação. A organização pesquisada implantou recentemente um programa interno de estímulo a novas ideias, que permite a contribuição de todos os colaboradores no processo de inovação. Ademais, ela também possui equipes que trabalham constantemente no desenvolvimento de soluções inovadoras para o mercado em que atua. Para a escolha dos participantes da pesquisa, a área de gestão da inovação da empresa indicou 44 pessoas que participaram de projetos de inovação. Destes, retornaram 9 questionários preenchidos. Para a obtenção dos dados, foi utilizada a técnica survey. O questionário utilizado foi Minnesota Innovation Survey (MIS), dividido em duas partes, com questões abertas e questões fechadas em escala Likert de 5 pontos que analisa 29 dimensões divididas nos fatores de influência: ideias, contexto, pessoas, transações e resultados. Para auxiliar no envio eletrônico e facilitar o preenchimento do questionário, foi utilizada uma plataforma para hospedagem de pesquisas, possibilitando aos respondentes acessar o questionário virtualmente.

\section{Descrição dos resultados obtidos}

Neste capítulo, estão descritos os resultados coletados pelo questionário aplicado aos membros da organização, que de alguma forma, participaram do processo de inovação. A análise seguinte apresenta as 29 dimensões observadas na organização. De acordo com Van de Ven, Angle e Poole (2000), quanto mais próxima dos níveis 4 e 5 na escala Likert, mais favorável à inovação é considerada a dimensão. A dimensão eficiência percebida com a inovação avalia o nível com que os envolvidos percebem como a inovação alcançou às expectativas. Os resultados demonstram que as pessoas que responderam o questionário estão, em média, bastante satisfeitos com o progresso ocorrido na inovação. É possível observar também, que para os respondentes, a eficácia da inovação foi considerada boa. A antecipação e solução de problemas foi percebida como muito boa por $75 \%$ dos participantes da pesquisa. Quanto ao progresso obtido com a inovação, $50 \%$ responderam que consideram um pouco acima das expectativas originais e $50 \%$ responderam que a inovação contribuiu bastante para o atingimento dos objetivos da empresa.

A incerteza sobre a inovação permite verificar a imprevisibilidade das ideias inovadoras. Van de Ven, Angle e Poole (2000) afirmam que quanto maior a incerteza sobre a inovação, menores serão os resultados propícios à inovação. A análise dos resultados visualizados demonstra que os 
participantes da pesquisa consideraram neutra a possibilidade saber com antecedência os passos corretos para desenvolver a inovação, pois a maioria das respostas indicou para o item "moderado". É possível afirmar também que, para os entrevistados, o tempo dedicado à inovação gerou resultados. Foi percebida uma baixa frequência de problemas de difícil solução na fase da inovação em que participaram e que não havia repetição dos problemas que surgiam. A dimensão escassez de recursos mensura as disputas por recursos e a pressão da carga de trabalho. Quanto mais centrais os valores atribuídos para o indicador de disputa por recursos, maiores são as chances das inovações acontecerem. Observa-se que as pessoas que responderam a pesquisa consideraram que poucas vezes houve sobrecarga de trabalho durante a fase da inovação em que participaram, demonstrando que a intensidade de trabalho é um item favorável à inovação na empresa em estudo. A competição por recursos apresentou resultados moderados, evidenciando que os recursos eram suficientes. As respostas evidenciam níveis moderados de competição, que de acordo com o MIS são favoráveis à inovação, pois a escassez de recursos tende a gerar uma direção em curto prazo, prejudicial à inovação tanto quanto o excesso de recursos.

Padronização de procedimentos representa o detalhamento e especificação das normas que servirão como diretriz para o processo de inovação. Procedimentos padronizados possibilitam o foco nas tarefas que demandam criatividade. De acordo com a metodologia utilizada, quanto mais documentadas e padronizadas as regras e atividades para o desenvolvimento da inovação, melhores serão seus resultados. É possível constatar, com base nos resultados que a quantidade de regras e procedimentos para a realização das atividades era pequena e que a precisão das regras e procedimentos em relação ao trabalho a ser executado foi considerada pela maioria dos pesquisados, como sendo específicas em parte. A dimensão padronização de procedimentos foi considerada como inibidora ao ambiente inovador na empresa em estudo. $O$ grau de influência nas decisões retrata a percepção dos participantes em relação às suas contribuições para o processo de inovação. As ideias construídas pelo grupo são mais fáceis de implementar, devido seu interesse e participação. Observando os resultados é possível afirmar que os envolvidos no processo de inovação tiveram forte influência na determinação de objetivos e na determinação das atividades para executar o processo, porém, foi percebido que não houve influência na determinação de recursos, nem no recrutamento de pessoas para trabalhar com a inovação.

Expectativas de prêmios e sanções observa a percepção da equipe quanto às recompensas pelo bom resultado. Relaciona-se com o sucesso da inovação, pois está diretamente ligada à motivação e satisfação no trabalho. De acordo com o método MIS, cobranças ou reconhecimento apenas sobre alguns indivíduos podem ser considerados como obstáculos à inovação. Nesta dimensão é possível perceber que a probabilidade de reconhecimento ou cobrança coletiva foi considerada respectivamente pelo grupo com $50 \%$ de chance e bastante provável de acontecer. As 
questões referentes à cobrança por melhoria no desempenho e pelo reconhecimento recair apenas sobre algumas pessoas, foi apontado pelo grupo, de forma respectiva, com 50\% de chance e com pequena chance de acontecer. A dimensão liderança do time de inovação refere-se à percepção dos entrevistados quanto à participação da liderança como promotores de um comportamento inovador. Quanto maior for o nível de liderança, mais os envolvidos no processo notarão a eficiência da inovação. Os participantes demonstram uma percepção favorável ao ambiente inovador. O encorajamento à tomada de iniciativas, a clareza sobre as responsabilidades individuais, a ênfase ao comprometimento com o resultado, a preocupação em manter o relacionamento entre os grupos e a confiança do líder no grupo, foram considerados, em média, pelos respondentes do questionário, como práticas que ocorrem frequentemente na organização. A aplicação de feedbacks construtivos foi apontado pelos participantes, como uma ferramenta utilizada em metade das vezes.

A liberdade para expressar dúvidas demonstra de que maneira os participantes da inovação visualizam as pressões para estar em conformidade com o grupo e com as normas da empresa. De acordo com a metodologia MIS, a facilidade para os envolvidos expressarem as opiniões proporcionam condições para um ambiente inovador. $\mathrm{O}$ grupo apresentou respostas que permitem interpretar que há liberdade para expressar dúvidas no ambiente analisado. A maioria dos participantes concordou parcialmente que as críticas construtivas e questionamentos são incentivados. Percebeu-se consenso também nos resultados que indicam que não existe pressão para ocultar opiniões sobre o que ocorre com o processo de inovação. Houve neutralidade nas respostas referentes ao questionamento da percepção de dúvidas sobre o rumo da inovação, que não tornaram-se públicas.

A aprendizagem encorajada retrata a percepção dos entrevistados quanto à valorização do aprendizado e dos riscos tomados e a minimização das consequências dos erros. Esta referência é encontrada com frequência em organizações que favorecem a inovação. Os resultados apresentados demonstram que a empresa incentiva o aprendizado. A média encontrada indica que os participantes da pesquisa, discordam parcialmente, que as falhas decorrentes de iniciativas impactam negativamente na carreira dos indivíduos e $75 \%$ concordam parcialmente que a organização valoriza os riscos e prioriza o aprendizado e a experimentação de novas ideias. Considera-se no presente estudo, que esta dimensão é favorável ao ambiente de inovação na empresa analisada. A dimensão dependência de recursos analisa a extensão em que as partes notam em sua interrelação a necessidade de recursos financeiros, informações, materiais da outra parte no desenvolvimento do processo. Quanto maior a dependência de recursos entre os grupos e o intercâmbio destes, maior a facilidade de condução do processo de inovação. Percebe-se que houve necessidade de colaboração entre os grupos. As médias observadas apontam a ocorrência de bastante ajuda recebida e ofertada para alcançar os objetivos. Em relação aos grupos executarem as 
tarefas de outros grupos, os resultados indicam uma posição neutra, dando o entendimento que as atividades eram cumpridas e distribuídas de uma forma equitativa entre os grupos.

A formalização no relacionamento reflete qual o nível de verbalização dos termos do relacionamento entre grupos. A formalização do processo de inovação garante controle e resultados. Esta dimensão foi considerada na pesquisa como influente de forma positiva no processo de inovação, pois os inquiridos na pesquisa consideraram que houve verbalização e descrição detalhada dos termos da relação entre os grupos. Através da eficiência percebida com o relacionamento é possível identificar de que maneira os envolvidos percebem se as atividades, compromissos e o relacionamento estão acontecendo de forma equilibrada. A distribuição uniforme de tarefas e o respeito entre as partes proporcionam um clima favorável à inovação. Houve elevados níveis de satisfação de relacionamento entre os grupos (50\% afirmam estar bastante satisfeitos), $62,5 \%$ dos indivíduos que responderam o questionário afirmam que aconteceu de forma recíproca o cumprimento de compromissos assumidos entre os grupos. Quanto ao retorno percebido sobre os esforços e recursos investidos, a totalidade das respostas aponta que foi equilibrado, mostrando que a distribuição equitativa das atividades é uma prática comum na organização. A influência entre grupos representa o poder de convencimento entre as partes. A parceria e o compartilhamento dos trabalhos e resultados são favoráveis à inovação. A análise mostra que 50\% dos participantes, consideraram que houve influência entre os grupos. A média encontrada demonstra que o resultado da parceria poderá ser bastante aproveitado em outros projetos e metas da empresa.

As questões referentes ao ambiente econômico possibilitam uma interpretação sobre a estrutura de mercado e concorrência. Ambientes econômicos estáveis, com pouca concorrência e fáceis de prever, são desfavoráveis à inovação. O ambiente econômico onde a inovação foi desenvolvida possui certa previsibilidade, porém foi considerado neutro quanto à variação e complexidade. É possível identificar na dimensão ambiente tecnológico a existência de outras unidades de pesquisa e desenvolvimento. Ambientes tecnológicos muito complexos atrapalham o processo de inovação. O ambiente tecnológico em que está inserida a inovação demonstra que é moderado quanto à estabilidade e previsibilidade. Quanto à complexidade, a média indica que foram necessários muitos esforços de desenvolvimento. São levados em consideração na análise do ambiente demográfico, os aspectos sociais, populacionais e níveis educacionais, que possam influenciar no ambiente em que está inserida a inovação. A complexidade do ambiente demográfico pode dificultar o processo de inovação. Os aspectos desta dimensão quanto à estabilidade, previsibilidade e complexidade, são em média neutros, não interferindo no processo de inovação.

Na dimensão ambiente legal/regulador é possível identificar de que forma são percebidas as políticas governamentais, incentivos e legislação. Quanto mais instável o ambiente que regula a inovação, maior a dificuldade de desenvolvimento. As políticas governamentais, regulações, 
incentivos e leis são considerados neutros quanto à influência no processo de inovação. O grau de novidade demonstra a classificação do trabalho desenvolvido. Pode representar uma adaptação de processos ou uma novidade original. A empresa em estudo é líder no segmento em que atua e desenvolve soluções pioneiras para o mercado. Tais fatores indicam que suas inovações podem ser consideradas originais. A dimensão da inovação permite verificar a quantidade de pessoas e recursos envolvidos no desenvolvimento da inovação. À medida que são disponibilizados recursos e pessoas suficientes, aumenta a possibilidade de resultados satisfatórios. Devido à inovação ser um assunto estratégico, certas informações exigem confidencialidade. Na presente pesquisa, não foi possível dimensionar os recursos financeiros e pessoas envolvidas no processo de inovação. A dimensão estágio da inovação demonstra se a inovação está na fase de concepção, na fase de implantação ou já está incorporada na organização. É percebida através da avaliação da situação em que a empresa se encontra em relação à inovação. Para a interpretação desta dimensão, foi considerado o momento presente, bem como as ações que estão sendo tomadas pela organização que demonstram o estágio da inovação. No segundo semestre de 2011, foi lançado na empresa em estudo, um programa interno de inovação, baseado no trinômio: Ideias, processos e valor, através de ações de estímulo e encorajamento a atitudes inovadoras, considerando que cada membro da equipe pode ser inovador no dia a dia. Considera-se que a fase atual é de implementação, com tendência à fase da incorporação, que acontecerá quando a cultura da inovação estiver completamente inserida no cotidiano da empresa.

A dimensão que trata do tempo dedicado à inovação determina qual o tempo e esforço fora da rotina das tarefas foi aplicado exclusivamente a projetos inovadores. $\mathrm{O}$ tempo dedicado à inovação entre os entrevistados foi em média de 24,78 horas semanais em um período normal considerado de 44 horas semanais, porém, houve grande dispersão nas respostas, possivelmente, devido à diferença das tarefas e atividades realizadas pelos entrevistados no período considerado para a pesquisa. A inovação representou moderado à grande esforço para os envolvidos. As atividades que mais demandaram tempo aos participantes da pesquisa foram os aspectos técnicos da inovação $(6,57 \mathrm{~h} /$ semanais em média), discussão sobre inovação com potenciais consumidores (6,5h/semanais em média), treinamento e estudo (6,33 h/semanais em média), coordenação da inovação junto a outros times (5,6 h/semanais em média). A frequência de comunicação refere-se à assiduidade com que as equipes de inovação comunicam-se internamente e externamente ao seu grupo. Indica o grau de interação do membro e as pessoas com quem manteve relacionamento durante o período em que participou do projeto de inovação. Para 62,5\% dos participantes da pesquisa, a comunicação pessoal sobre problemas, era feita semanalmente por outros indivíduos que estavam trabalhando com a inovação. É possível constatar que a mesma comunicação era realizada mensalmente por pessoas de outros departamentos, gerentes, consultores externos, consumidores e 
fornecedores. Na opinião dos respondentes, não houve contato com pessoas do governo ou agências reguladoras, para recebimento de comunicação pessoal referente a problemas da inovação. Esta dimensão foi considerada como um fator inibidor à inovação no presente trabalho.

A dimensão problemas identificados permite observar os obstáculos vivenciados no desenvolvimento de uma inovação no decorrer do tempo. Um número elevado de obstáculos pode dificultar a implementação bem sucedida da novidade. Esta dimensão foi considerada moderadamente favorável à inovação, pois houve pouca dificuldade de recrutamento de pessoal, houve certa clareza sobre objetivos e compreensão sobre como implementar objetivos. A questão que trata de suporte ou resistência de algumas pessoas chave foi considerada, em média, como sendo pouco vivenciada. Problemas em coordenar aspectos do processo de inovação com outras unidades da organização e falta de recursos financeiros foram considerados neutros. Os problemas descritos pelos entrevistados estão relacionados à integração de sistemas, visão diferenciada sobre temas do dia a dia ou outras formas de utilizar/desenvolver produtos rotineiros, alocação de recursos para a inovação, agendamento de entrevistas com executivos, aprovação de budget, garantia da margem elevada de assertividade de indicadores. Na dimensão conflitos são tratados dois tipos de disputas no time: frequência com que ocorrem e proteção de unidades. Comportamentos de autoproteção acarretam em obstáculos ao sucesso da inovação. Houve grande facilidade de inter-relação entre os grupos e os conflitos entre as pessoas relacionadas com a inovação, ocorreram com pouca frequência. A dimensão referente aos conflitos pode ser considerada nesta pesquisa, como um fator de influência positiva para o processo de inovação.

Na dimensão processo de resolução de conflitos são identificadas as formas como são tratadas as situações conflitantes. Um índice elevado de controle de conflitos é adequado ao ambiente inovador. Os participantes da pesquisa informaram que no período em participaram do processo de inovação, quando ocorreram desentendimentos, poucas vezes as questões foram evitadas ou abordadas superficialmente. As questões de disputas eram trazidas à tona para serem trabalhadas com os envolvidos em média na metade das vezes que aconteciam. Quanto à frequência de comparação dos problemas com as metas originais, a ocorrência foi em metade das vezes. Uma ação favorável identificada nesta dimensão é a baixa recorrência a um nível superior para solução de desentendimentos, comprovando o consenso e o poder de decisão dos indivíduos. A complementaridade representa a sinergia e a reciprocidade entre as partes relacionadas. Um elevado nível de complementaridade indica que há poucas disputas, sendo favorável à inovação. A média de respostas mostra que na percepção dos inquiridos, houve bastante complementação dos objetivos entre os grupos. Observa- se também nesta dimensão, que os participantes, consideraram que o resultado da parceria poderá ser bastante aproveitado em outros projetos e metas da empresa. 
A dimensão consenso/conflito trata do nível de aceitação e discordância entre as partes relacionadas e a confiança existente. Quanto maior o nível de consenso e confiança, maiores são as chances de sucesso. Houve pouca competição entre os grupos durante o processo de inovação e havia bastante confiança entre as pessoas dos grupos. A ocorrência de conflitos entre os times foi considerada baixa pelos participantes, com uma frequência mensal ou menos. A frequência da comunicação entre grupos analisa a assiduidade com que aconteceram contatos entre as partes relacionadas no processo de inovação. Quanto mais elevado este indicador, mais positivos serão os resultados para a inovação. A análise demonstra que para os indivíduos que responderam a pesquisa, diariamente havia comunicação ou contato entre os elementos dos grupos participantes. Fator importante para o sucesso da inovação. A duração do relacionamento refere-se ao tempo de permanência do relacionamento que iniciou no processo de inovação, representando um contato positivo entre os grupos. Percebe-se que os participantes do estudo, em média, consideraram que o relacionamento durou de 2 a 3 anos após o término da implantação da inovação.

\section{Discussão dos resultados}

As dimensões do método MIS foram distribuídas nos fatores de influência: ideias, pessoas, contexto, transações, natureza e resultado. Com base nas respostas obtidas no questionário e condições observadas na empresa, foram atribuídos níveis de contribuição das dimensões para o ambiente de inovação (descritos no Quadro 2).

Quadro 2 - Contribuição das dimensões identificadas na pesquisa

\begin{tabular}{|l|l|l|}
\hline Dimensão & Fator de influência & Contribuição identificada \\
\hline Eficiência percebida com a inovação & Resultados & Moderada \\
\hline Incerteza sobre a inovação & Ideias & Moderada \\
\hline Escassez de recursos & Contexto & Alta \\
\hline Padronização de procedimentos & Transações & Baixa \\
\hline Grau de influência nas decisões & Pessoas & Neutra \\
\hline Expectativa de prêmios e sanções & Contexto & Neutra \\
\hline Liderança do time de inovação & Pessoas & Alta \\
\hline Liberdade para expressar dúvidas & Contexto & Moderada \\
\hline Aprendizagem encorajada & Contexto & Alta \\
\hline Dependência de recursos & Transações & Moderada \\
\hline Formalização no relacionamento & Transações & Moderada \\
\hline Eficiência percebida com relacionamento & Transaç̃̃es & Alta \\
\hline Influência entre grupos & Transações & Moderada \\
\hline Ambiente econômico & Contexto & Neutra \\
\hline Ambiente tecnológico & Contexto & Neutra \\
\hline Ambiente demográfico & Contexto & Neutra \\
\hline Ambiente legal/regulador & Contexto & Neutra \\
\hline Grau de novidade & Natureza & Alta \\
\hline Dimensão da inovação & Natureza & - \\
\hline Estágio da inovação & Natureza & Moderada \\
\hline Tempo dedicado à inovação & Pessoas & Moderada \\
\hline Frequência da comunicação & Transações & Baixa \\
\hline Problemas identificados & Transaçoses & Moderada \\
\hline Conflitos & Transac̃oes & Alta \\
\hline Processo de resolução de conflitos & Transações & Moderada \\
\hline Complementaridade & Transaçoses & Moderada \\
\hline Consenso/conflito & Contexto & Alta \\
\hline
\end{tabular}




\begin{tabular}{|l|l|l|}
\hline Frequência da comunicação entre grupos & Transações & Moderada \\
\hline Duração do relacionamento & Transações & Alta \\
\hline
\end{tabular}

Fonte: Autoria própria

A seguir, serão analisados os resultados das dimensões, percebidos pelos entrevistados, em cada um dos fatores de influência. $\mathrm{O}$ fator de influência ideias, estudado pelo grupo MIRP, permite analisar se a organização dispõe de instrumentos para incentivar a geração de ideias, bem como os mecanismos de disseminação. A empresa em estudo desenvolveu um método de captação e administração de ideias, que consiste numa plataforma colaborativa de estímulo a novidades, visando à inovação como parte do dia a dia de todos. A iniciativa assemelha-se a uma "bolsa" de ideias, em que qualquer membro da empresa pode propor uma ideia, que se for aprovada, terá visibilidade para toda a organização, funcionando como uma rede social em que os funcionários podem dar nota para as novidades, opinar e realizar investimentos em moeda virtual. As propostas mais investidas são avaliadas por uma equipe multidisciplinar, com possibilidades de implantação total de uma iniciativa, criação de um projeto, ou mesmo o lançamento de um novo produto ou serviço. No estudo foi possível perceber que o nível de incerteza sobre a inovação, dimensão relacionada com as ideias, apresentou resultado moderado, indicando que este fator, de certa forma, influi de maneira positiva na construção de um ambiente de inovação.

De acordo com a metodologia MIS, o contexto é o panorama ou ambiente institucional em que as ideias de inovação são ampliadas e transacionadas entre os envolvidos. O processo de inovação deve considerar uma visão macro, referindo-se à infraestrutura organizacional necessária para implantar e comercializar uma inovação. As informações obtidas indicam que o contexto da empresa é propício a novas ideias. Foi identificada influência positiva das dimensões escassez de recursos, aprendizagem encorajada, consenso de conflitos e liberdade para expressar dúvidas. As dimensões expectativas de prêmios e sanções e os fatores externos obtiveram uma classificação neutra, não interferindo no ambiente de inovação da empresa em estudo. O contexto favorável à inovação foi percebido também, em ações promovidas pela empresa, como o programa Pesquisas Aplicadas, que tem como objetivo o incentivo e apoio para pesquisas acadêmicas, gerando novos conhecimentos e inovação, atendendo os interesses do meio acadêmico e as necessidades organizacionais. O público alvo do programa são alunos de programas de pós-graduação e pesquisadores (já titulados mestres ou doutores), que possuam vínculos com instituições de pesquisa. O programa oferece bolsas de pesquisa e recebe inscrições anualmente para projetos que se enquadrem nos temas de estudo de interesse da empresa.

Para Van de Ven, Angle e Poole (2000), a associação de pessoas resulta na interação de diferentes habilidades, níveis de energia e percepções que favorecem as inovações. Foi possível identificar forte contribuição da dimensão liderança do time de inovação, sobretudo pelo resultado 
das questões que se referem ao incentivo de iniciativas, clareza sobre responsabilidades e confiança da liderança sobre o grupo, que apresentaram índices elevados de concordância entre os entrevistados. A dimensão tempo dedicado à inovação apresentou resultados moderados e a dimensão grau de influência nas decisões demonstrou resultados neutros no meio estudado. Com base nessas informações, pode-se considerar que o fator referente a pessoas, apresentou contribuição moderada, porém positiva na construção de um ambiente de estímulo a ideias.

$\mathrm{O}$ fator de influência transações representa as relações pertinentes ao gerenciamento de inovações, de acordo com o método utilizado neste estudo. Abrangem o relacionamento entre colegas, líderes e entre subordinados, comprometimento para captar e destinar recursos, envolvimento entre diferentes unidades, grupos ou organizações para obter recursos para desenvolver as inovações. Neste fator foram identificadas duas dimensões avaliadas pelos participantes da pesquisa, como inibidoras da inovação. A padronização de procedimentos para realizar atividades no processo de inovação, apesar da empresa possuir normas e guias de operação para a execução das atividades, foi considerada baixa, possivelmente por se tratar de projetos inéditos que ainda não estão normatizados. Outra dimensão considerada como empecilho à inovação neste estudo foi a frequência da comunicação. De acordo com a média das respostas obtidas, a comunicação feita pessoalmente referente a problemas com a inovação, ocorreu em média, mensalmente, frequência considerada baixa pela metodologia aplicada. Em contrapartida, verificou-se uma grande ocorrência de dimensões avaliadas como positivamente influentes no processo de inovação: baixa incidência de problemas, nível reduzido de conflitos, frequência da comunicação entre grupos, processo de resolução de conflitos, influência entre grupos, complementaridade, duração do relacionamento, dependência de recursos, eficiência percebida com o relacionamento e formalização do relacionamento.

Segundo Van de Ven, Angle e Poole (2000), os fatores relativos à natureza; compreendidos nas dimensões novidade, escopo, tamanho e estágio da inovação; são medidos com outras ferramentas (não do questionário MIS) e servem para observar a teoria básica contingencial do método MIS. No estudo, os itens referentes à natureza da inovação, foram analisados com base na observação das ações adotadas pela empresa em relação ao tema. Esse fator teve uma contribuição positiva na empresa pesquisada, devido ao lançamento constante de produtos e serviços inéditos no seu mercado de atuação e também, pela busca da cultura de inovação, através de um programa interno, já implementado, de incentivo e encorajamento a atitudes inovadoras. Os resultados são percebidos em um momento específico, após o desenvolvimento e aplicação da novidade, que pode se tornar uma inovação ou resultar em falha. A dimensão eficiência percebida com a inovação apresentou um nível de influência moderadamente positiva, podendo ser considerada como favorável ao meio inovador, principalmente pelos resultados das questões satisfação com o 
progresso da inovação e contribuição da inovação para alcançar os objetivos da empresa, demonstrando que os envolvidos com os processos inovadores estão motivados com o andamento da inovação e satisfeitos em contribuir com os objetivos da organização em estudo.

\section{Conclusão}

O objetivo do estudo foi identificar características que potencializam ou inibem a inovação no ambiente de uma empresa de informações para decisão de negócios. Para isso, foi utilizada a metodologia do Minnesota Innovation Survey (MIS), baseada em 29 dimensões que analisa fatores internos e externos de influência no ambiente inovador. A interpretação das informações coletadas através método MIS e as observações sobre a maneira como a empresa aborda o tema inovação, respondem a questão da pesquisa e atendem o objetivo principal, permitindo afirmar que a empresa analisada possui um ambiente inovador. Foram identificadas características favoráveis à inovação em 20 dimensões e apenas 2 dimensões apresentaram características desfavoráveis. Houve forte influência positiva das dimensões: liderança do time de inovação, aprendizagem encorajada, eficiência percebida com o relacionamento, escassez de recursos, grau de novidade, conflitos, duração do relacionamento e consenso/conflito. Foi possível perceber influência moderada, porém positiva, das dimensões: eficiência percebida com a inovação, incerteza sobre a inovação, liberdade para expressar dúvidas, dependência de recursos, formalização no relacionamento, influência entre grupos, tempo dedicado à inovação, estágio da inovação, frequência da comunicação entre grupos, problemas identificados, processo de resolução de conflitos e complementaridade. As dimensões padronização de procedimentos e frequência da comunicação foram consideradas inibidoras da inovação. As demais dimensões estudadas pelo método MIS apresentaram resultados neutros, ou seja, não interferiram positivamente, nem negativamente no ambiente analisado.

O presente trabalho contribui com a difusão do conhecimento sobre a relação entre o ambiente organizacional e a inovação, permitindo à empresa pesquisada estimular iniciativas que potencializem o desenvolvimento da inovação, com base nos fatores de contribuição identificados no ambiente. Apesar dos resultados obtidos, houve uma limitação do estudo devido ao baixo retorno das pesquisas respondidas, possivelmente pela extensão do questionário e pela escassez de tempo em razão da pesquisa ter sido realizada em ambiente corporativo de uma empresa com características de alto desempenho. Com base nessa limitação, sugere-se aos trabalhos futuros, a adaptação do questionário MIS, com a realização do estudo sobre todas as dimensões, porém reduzindo o número de questões de cada dimensão, sem alterar as características básicas da ferramenta. 


\begin{abstract}
The importance of this theme on innovation and the wish to contribute to the academic and enterprising community warrants this study. The purpose of this research has been to identify characteristics in favorable surroundings to encourage innovations in an information technological company for making business decisions. The steps for performing the research have included studying theoretical references in publications on innovation, surveying data on the main historical facts on the company, and collecting data from the Minnesota Innovation Survey (MIS) questionnaire to analyze 29 dimensions divided into these influential factors: ideas, people, transactions, and results. This study is characterized as descriptive and quantitative. This study has displayed its analysis results on the influential factors on the surroundings and their contribution on carrying out the innovation process in the researched company, thus, making it possible to confirm that the analyzed surroundings are conducive to innovation, evidenced by such dimensions as: Efficiency of innovation, uncertainty about the innovation, freedom to express doubts, resource dependence, formalization of the relationships, influence among groups, stage of innovation, identification of problems, complementarity, innovative team leadership, encouragement for learning, efficiency of relationships, resource scarcity, the level of novelty, conflicts, problem solving, relation time spans, time dedicated to innovation, frequency communication among groups and consensus. The analysis identified only two dimensions hampering innovation: the standardization of procedures and communication frequency.
\end{abstract}

Key-words: Innovation; Innovative environment; Organization.

\title{
Referências
}

AFUAH, A. Innovation mangement: strategies, implementation and profits. New York: Oxford University Press, 2003.

ALTER, N. Inovação, Risco e Transgressão nas Organizações. In: DAVEL, Eduardo; VERGARA, S. C. (Organizadores). Gestão com Pessoas e Subjetividade. São Paulo: Atlas, 2001.

BARBIERI, J. C.; ÁLVARES, A. C. T. Inovações nas organizações empresariais. In BARBIERI, J.C. (Org.). Organizações inovadoras. 2.ed. Rio de Janeiro: FGV Editora, 2004.

BARZOTTO, L. C. O ambiente de inovação em instituição hospitalar. Dissertação (Mestrado em Administração) Fundação Universidade Regional de Blumenau - FURB. Blumenau. 2008

GOVINDARAJAN, V.; TRIMBLE, C. O outro lado da inovação: A execução como fator crítico de sucesso. Rio de Janeiro: Elsevier, 2010.

KNOP, A.V. H. Um Estudo Exploratório sobre os Fatores Habilitadores e Inibidores da Inovação Organizacional em Empresas Canadenses Prestadoras de Serviços Profissionais para o Mercado de Telecomunicações.

Dissertação de Mestrado. São Paulo: FGV, 2008.

LEITE, L.F. Inovação: o combustível do futuro. Rio de Janeiro: Qualitimark, 2005.

MATSUZAWA, C. M. Inovação em Saúde: Estudo de Casos - Dissertação (Mestrado Administração de Empresas) Fundação Getúlio Vargas - FGV. São Paulo. 2008.

NONAKA, I.; TAKEUCHI, H. Criação de conhecimento na empresa. Rio de Janeiro: Campus, 1997.

OCDE, Organização para Cooperação e Desenvolvimento Econômico, Manual de Oslo, 2005.

TUSHMAM Michael; NADLER, David. Organizando-se para a inovação In: STARKEY, Ken. Como as Organizações Aprendem: Relatos do sucesso das grandes empresas. São Paulo: Futura, 1997. 
VALADARES, R. L. Ambientes organizacionais potencializadores em bases sistemáticas: estudo de caso do Hospital Jorge Valente - Dissertação (Mestrado Administração) - Universidade Federal da Bahia - UFBA. Salvador. 2008

VAN DE VEN, A. H.; ANGLE, H. L.; POOLE, M. S. Research on the management of innovation: the Minnesota studies. New York: Oxford University Press, 2000.

VICENTI, T. Ambiente de inovação nas empresas de software de Blumenau Santa Catarina - Brasil. 2006. Dissertação (Mestrado Administração de Empresas) - Fundação Universidade Regional de Blumenau - FURB. Blumenau. 2006.

\section{Dados completos dos autores:}

Nome completo: Marcelo Macedo

Filiação institucional: Instituto Superior Tupy/SOCIESC

Departamento: Mestrado Profissional em Engenharia de Produção

Função ou cargo ocupado: Professor/pesquisador.

Endereço completo para correspondência (bairro, cidade, estado, país e CEP):

Rua Praia Grande, 1235, Comasa, Joinville, SC, Brasil - CEP 89228-100

Telefones para contato: Tel. 47- 9600-7906

e-mail: marcelo.macedo@sociesc.org.br

Nome completo: Márcia Adriana Tomaz Duarte

Filiação institucional: Instituto Superior Tupy/SOCIESC

Departamento: Mestrado Profissional em Engenharia Mecânica

Função ou cargo ocupado: Professora/pesquisadora.

Endereço completo para correspondência (bairro, cidade, estado, país e CEP):

Rua Clara Nunes, P3 - Nova Brasilia CEP: 89214-450

Telefones para contato: Tel. 47- 9600-7906

e-mail: marcia.duarte@sociesc.org.br

Nome completo: Leonardo Muller

Filiação institucional: Instituto Superior Tupy/SOCIESC

Departamento: Mestrado Profissional em Engenharia de Produção / Empresa Serasa Experian Função ou cargo ocupado: Discente / Gerente de Operações

Endereço completo para correspondência (bairro, cidade, estado, país e CEP): Rua Tijucas, 246 ap 12 - América CEP: 89204-020

Telefones para contato: Tel. 47-9147 6375

e-mail: leomuller13@gmail.com

Enviado em: 04/12/2012

Aprovado em: 22/01/2013 